\title{
The ecological state assessment of the flora and vegetation in the parks of cities in the steppe zone of Khakasia
}

\author{
Elena Yu. Zhukova ${ }^{1}$, and Elena G. Lagunova ${ }^{1}$ \\ ${ }^{1}$ Federal State-Funded Educational Institution of Higher Education «Katanov Khakass State \\ University», 655017, Lenin Avenue 90, Abakan, Russia
}

\begin{abstract}
A study of parkland in Abakan and Chernogorsk cities, located in the steppe zone and characterized by a high level of atmospheric pollution. Plant taxa are identified that make the greatest contribution to the purification of the urban environment. The most common tree plants in the parkland are adventitious species Populus alba L., P. balsamifera L., Acer negundo L., Sorbaria sorbifolia (L.) A. Braun, Syringa vulgaris L., Ulmus pumila L. et al. In the flora of parks and squares of Abakan, 288 species of higher vascular plants belonging to 59 families and 183 genera were identified. The flora of parkland in Chernogorsk totals 142 species belonging to 33 families and 105 genera. Leading position belongs to the largest families Asteraceae, Poaceae, Rosaceae and Fabaceae. An analysis of satellite data made it possible to remotely determine the functional state, phenological changes, and weather sensitivity of green zone vegetation. As a result of the studies, the general and seasonal indicators of the vegetation and water index were analyzed according to the satellite data (Landsat 8) for the territories of Abakan and Chernogorsk located in the steppe zone of Khakasia. Abakan had higher values of the integral NDVI (45.1-57.9), in comparison with Chernogorsk (11.4-14.2), better water supply and earlier dates of the beginning of the growing season. Based on satellite data, the productivity of green zones was compared and the regression dependences of spectral and meteorological indicators were identified.
\end{abstract}

\section{Introduction}

Abakan and Chernogorsk cities are located in the zone of increased natural and anthropogenic potential for atmospheric pollution, which is characterized by frequent repeatability of calm and surface inversions, which prevents the dispersion of pollutants and contributes to their accumulation. As ecological monitoring of vegetation in the urban environment is limited, the value of data on species diversity is increasing. It is of interest to compare the species composition of various cities with remote sensing, as this characterized the adaptation of species to environment, the diversity of ecological and biomorphological forms in specific circumstances. As a result, urban vegetation needs constant monitoring, for that terrestrial and satellite data are successfully applied [1-3].

The purpose of the study was to assess the current state of the flora and vegetation in the parks of cities in the steppe zone of Khakasia according to ground and satellite data.

\section{Methods}

Abakan and Chernogorsk are located in the Minusinsk depression, which occupies the central, lowest region at an altitude of 250-300 m above sea level. This territory belongs to the Abakan steppe district on the territory of the Uibat plain-hilly solonetzic region. The climate of the research 
sites is sharply continental. Atmospheric moisture is unstable and uneven. Average air temperature in July: $+17.9^{\circ} \mathrm{C}$, in January: $-18.9^{\circ} \mathrm{C}$.

Due to the synanthropization and degradation of the vegetation cover in the conditions of the studied cities, urban vegetation can be divided into cultivated (garden-park complexes, lawns) and natural (steppes, forests and meadows). Natural vegetation, preserved on the territory of cities fragmented, is slightly represented in the residential zone. Steppes, valley meadows and poplar forests are widespread in Abakan vicinity, vegetation develops under the influence of natural steppe vegetation surrounding the city and synanthropic vegetation. The hydrology of Abakan city, associated with the close location of the Yenisei, Abakan and Tasheba rivers, has a strong influence on vegetation. Chernogorsk city is surrounded by small-grained steppes. Soils in cities are poor and require land reclamation measures.

The collection of higher vascular plants in the cities of Abakan and Chernogorsk was carried out by the route method for different phenological periods from 2012 to 2018: in spring (May), summer (June-August), and autumn (early September). For the collection and herbarization of plants, a traditional technique was used. The collected plants was determined in laboratory conditions [4-5]. The floral list was compiled on the basis of our own collections, literature data and the scientific herbarium of KhSU named by N.F. Katanov. The classification by T.G. Goryshina [6], based on the ratio of plants to substrate moisture, was used for an ecological analysis of the flora. Biomorphological analysis is based on the classification by I.G. Serebryakov [7].

Landsat 8 images used in the work (http://glovis.usgs.gov/):

1. radiometric correction of Landsat 8 for 2017, cloudless images (14.05.15; 04.06.17; 20.06.17; 06.07.17; 20.07.13; 07.08.17; 20.08.16; 05.09.16) by GRASS GIS;

2. calculation of the spectral indices NDVI, NDWI [8], growth rate. To calculate the integral NDWI (Table 2), the data without correction were used (positive values), and adjusted images (negative numbers) were used for seasonal dynamics;

3. statistical analysis (mean and standard deviation), regression analysis with weather data (sum of positive temperatures and hydrothermal coefficient, HTC) (https://rp5.ru).

\section{Results}

288 species of higher vascular plants belonging to 59 families and 183 genera were identified in the flora of parks and squares of Abakan city. The basis of the flora is angiosperms, including 57 families (96.6\%), 179 genera (97.8\%), 282 species $(97.9 \%)$. Vascular spore plants include 1 family of Equisetaceae (1.7\%), 1 genus - Equisetum $(0.6 \%)$ and 2 species $(0.7 \%)$ : Equisetum arvense L., E. pratense L. The gymnosperm plants include 1 family - Pinaceae (1.7\%), 3 genera - Larix, Picea, Pinus (1.6\%) and 4 species (1.4\%): Larix sibirica Ledeb., Picea obovata Ledeb., Picea pungens Engelm., Pinus sylvestris $\mathrm{L}$. Representatives of these families are background. The leading position belongs to the largest families Asteraceae, Poaceae, Rosaceae, Fabaceae (Table 1).

The flora of the park and squares of Chernogorsk city totals 142 species of higher vascular plants belonging to 33 families and 105 genera. The largest systematic group is the group of angiosperms in the flora of the study area. It includes 32 families $(97.0 \%$ of the total number of families), 101 genera (96.2\%) and 138 species (97.2\%). Dicotyledonous and monocotyledonous plants are distinguished among those angiosperms. Monocotyledons were presented 3 families $(9.1 \%$ of the total number of families), including 15 genera (14.3\%) and 18 species (12.7\%). Dicotyledons consist of 29 families $(87.9 \%), 86$ genera $(81.9 \%)$ and 120 species $(84.5 \%)$. Gymnosperms included one family Pinaceae (3.0\%), 4 genera (3.8\%) and 4 species (2.8\%): Abies sibirica Ledeb., Larix sibirica, Picea obovata, Pinus sylvestris. 
Table 1. Family spectrum of flora of the cities of Abakan and Chernogorsk

\begin{tabular}{|l|c|c|c|c|}
\hline \multirow{2}{*}{ Family } & \multicolumn{2}{|c|}{ Abakan } & \multicolumn{2}{c|}{ Chernogorsk } \\
\cline { 2 - 5 } & $\begin{array}{l}\text { number of } \\
\text { species }\end{array}$ & $\begin{array}{l}\text { share of the total } \\
\text { number of species of } \\
\text { flora, \% }\end{array}$ & $\begin{array}{l}\text { number of } \\
\text { species }\end{array}$ & $\begin{array}{l}\text { share of the total } \\
\text { number of species of } \\
\text { flora, \% }\end{array}$ \\
\hline Asteraceae & 34 & 11.8 & 25 & 17.6 \\
\hline Poaceae & 31 & 10.8 & 16 & 11.3 \\
\hline Rosaceae & 31 & 10.8 & 15 & 10.6 \\
\hline Fabaceae & 21 & 7.3 & 15 & 10.6 \\
\hline Brassicaceae & 16 & 5.5 & 12 & 8.5 \\
\hline Ranunculaceae & 11 & 3.8 & 6 & 4.2 \\
\hline Lamiaceae & 10 & 3.5 & 8 & 5.6 \\
\hline Cyperaceae & 9 & 3.1 & 1 & 0.7 \\
\hline Boraginaceae & 8 & 2.8 & 4 & 2.8 \\
\hline Caryophyllaceae & 8 & 2.8 & 6 & 4.2 \\
\hline \multicolumn{1}{|c|}{ Bceго: } & 179 & 62.2 & 108 & 76.1 \\
\hline
\end{tabular}

The ten leading families in the Abakan city flora account for $62.2 \%$ of the species composition of the parkland flora and $76.1 \%$ of the Chernogorsk city flora.

Leading position belongs to the largest families Asteraceae, Poaceae, Rosaceae, Fabaceae. The role of the Brassicaceae family is also great, the abundance of which is determined mainly by the anthropogenic factor. A high proportion of this family is a diagnostic sign of the urban flora [9].

Species distributed by humans were Capsella bursa-pastoris (L.) Medik., Berteroa incana (L.) DC, Descurainia sophia (L.) Webb ex Prantl, Lepidium ruderale L. et al. The high position in the family spectrum of the Rosaceae family is explained by the presence of numerous tree-shrub adventive species, which are widely used in urban landscaping. Representatives of the Rosaceae family are: Pyrus ussuriensis Maxim., Rosa majalis Herrm.,Padus avium Mill., Spiraea chamaedryfolia L., Sorbus sibirica Hedl., Sorbaria sorbifolia (L.) A. Braun et al.

Representatives of the Fabaceae family are characterized by high adaptation of species to urbanization conditions (Trifolium pratense L., Amoria repens (L.) C. Presl, Medicago sativa L., Onobrychis arenaria (Kit.) DC., Vicia cracca L. et al.).

The Cyperaceae family includes 9 species in the Abakan city flora, which is $3.1 \%$ of the total number of species (Carex acuta L., C. duriuscula C.A. Mey., C. cespitosa L., C. enervis C.A. Mey., C. dichroa (Freyn) V. Krecz, Eleocharis palustris L. et al.).

This family is represented by one species in the Chernogorsk flora - Carex duriuscula C.A. Mey. The role of this family in the urban flora is significantly reduced, compared with the natural flora, where it is one of the leading and ranks third in the family spectrum of the flora of Khakasia [10]. This is due to the fact that species of Cyperaceae family are deprived of their respective habitats in the city. According to M. A. Berezutsky (1998), it is this family that can be used as an indicator of the degree of anthropogenic floristic transformation [11].

Environmental analysis showed that the majority of the flora of the studied cities is mesophytes. They number 131 species $(45.5 \%$ of the total number of species) in the Abakan flora, for Chernogorsk $-39.1 \%$. Such an indicator is quite natural, since it meets the conditions of habitats prevailing in the city. The group of mesoxerophytes which combines 75 species or $26.0 \%$ of the total number of identified species in the Abakan flora is in second place, and 63 species $(31.2 \%)$ in Chernogorsk city. Plants belonging to this group grow along roads, paths, in steppe meadow plots, along the outskirts of tree stands. A group of xerophytes is significant, because it has 39 species (13.5\%) in Abakan and 49 
species $(24.3 \%)$ in Chernogorsk. Since the city of Chernogorsk is located in the steppe zone, where there are no water sources, the number of xerophytic species is higher here than in Abakan. There are quite a lot of hygrophytes (22 species or $7.6 \%$ of the total number of species), mesogyrophytes - 17 species (6.0\%), hydrophytes are less common and are represented by only 4 species (1.4\%) in the conditions of Abakan. There are enough habitats in the study area that have a favorable water regime (meadows, banks of drainage channels, etc.) where favorable conditions are created for the growth of species - hygroand hydrophytes. Naturally, mesogyrophytes (2.5\%) and hygrophytes $(1.5 \%)$ are represented slightly in Chernogorsk.

The predominant biomorphs are grassy polycarps. There are 165 species $(57.3 \%)$ in the Abakan flora; there are 74 species (52.1\%) in the Chernogorsk one. Monocarpic plants (45 species, or $15.6 \%$ in Abakan and 38 species, or $26.8 \%$ in Chernogorsk), many of which belong to weed species; ones are settled in the studied territories by humans or animals.

Urban areas need a certain level of landscaping depending on environmental conditions. Abakan parkland totaled $24.5 \mathrm{~km}^{2}$, or $21.9 \%$ (Table 2).

Table 2. The area, the productivity and the growth rate of green areas of Abakan (2017) and Chernogorsk (2016)

\begin{tabular}{|l|c|c|c|c|c|}
\hline \multirow{2}{*}{ Zone } & \multicolumn{5}{|c|}{ Abakan } \\
\cline { 2 - 6 } & $\mathrm{S}, \mathrm{km}^{2}$ & $\begin{array}{c}\text { \% of S } \\
\text { city }\end{array}$ & NDVI & NDWI & growth rate $^{*}$ \\
\hline Preobrazhenskiy park & 0.9 & 0.8 & $50.4 \pm 2.1$ & $20.4 \pm 7.1$ & 0.014 \\
\hline Square «Rainbow» & 0.5 & 0.4 & $45.1 \pm 2.2$ & $16.9 \pm 6.8$ & 0.036 \\
\hline Lake st. & 1.3 & 1.1 & $57.9 \pm 2.5$ & $32.4 \pm 7.4$ & 0.275 \\
\hline Krylova st. & 0.6 & 0.6 & $51.4 \pm 2.4$ & $22.8 \pm 8.1$ & 0.017 \\
\hline Park of culture & 8.3 & 7.4 & $56.8 \pm 2.5$ & $29.8 \pm 6.9$ & 0.118 \\
\hline Hippodrome & 0.4 & 0.3 & $49.7 \pm 2.4$ & $21.8 \pm 7.1$ & 0.114 \\
\hline Chernogorskiy park & 1.4 & 1.3 & $48.5 \pm 2.3$ & $20.4 \pm 7.3$ & -0.030 \\
\hline Park "Eaglet & 1 & 0.9 & $50.0 \pm 2.4$ & $23.6 \pm 9.1$ & 0.070 \\
\hline Soviet st. & 6 & 5.4 & $51.4 \pm 2.2$ & $23.6 \pm 9.1$ & 0.284 \\
\hline Park "Komsomolskiy" & 4.2 & 3.7 & $50.4 \pm 2.3$ & $22.1 \pm 9.9$ & 0.095 \\
\hline & & & Chernogorsk & \\
\hline City park & 0.30 & 1.17 & $12.3 \pm 0.1$ & $10.2 \pm 0.1$ & 0.517 \\
\hline Square «Young tourist» & 0.02 & 0.09 & $14.2 \pm 0.1$ & $11.4 \pm 0.1$ & 0.632 \\
\hline New Year's square & 0.10 & 0.51 & $13.3 \pm 0.1$ & $10.6 \pm 0.1$ & 0.539 \\
\hline Square «Stream» & 0.02 & 0.08 & $11.4 \pm 0.1$ & $8.2 \pm 0.1$ & 0.664 \\
\hline Square «MultiDom» & 0.01 & 0.05 & $14.2 \pm 0.1$ & $11.7 \pm 0.1$ & 0.492 \\
\hline School square (№ 19) & 0.07 & 0.30 & $13.8 \pm 0.1$ & $10.8 \pm 0.1$ & 0.589 \\
\hline School square (№ 20) & 0.03 & 0.14 & $11.8 \pm 0.1$ & $9.0 \pm 0.1$ & 0.605 \\
\hline
\end{tabular}

* - growth of NDVI during the period of maximum plant growth (from June 04 to July 06), \% NDVI for 1 day

The results of a quantitative assessment of the total productivity of the vegetation of Abakan showed that the plots did not differ much among themselves, in contrast to Chernogorsk, located in more arid conditions and in the immediate vicinity of the highway and the coal mine. The most part of Abakan city parkland had the indicator (NDVI for vegetation season) of 50.4-51.4, the most productive communities (Lake St. and Park of 
culture had indicators of 57.9 and 56.8). The lowest indicators were at the square «Rainbow» (45.1).

The period of growth of plants in parkland depends on the structural and functional characteristics of communities. The maximum was observed on Lake st. and Soviet st. (0.275 and 0.284 , respectively).

The dynamics of NDVI is presented to identify phenological changes (Fig. 1).

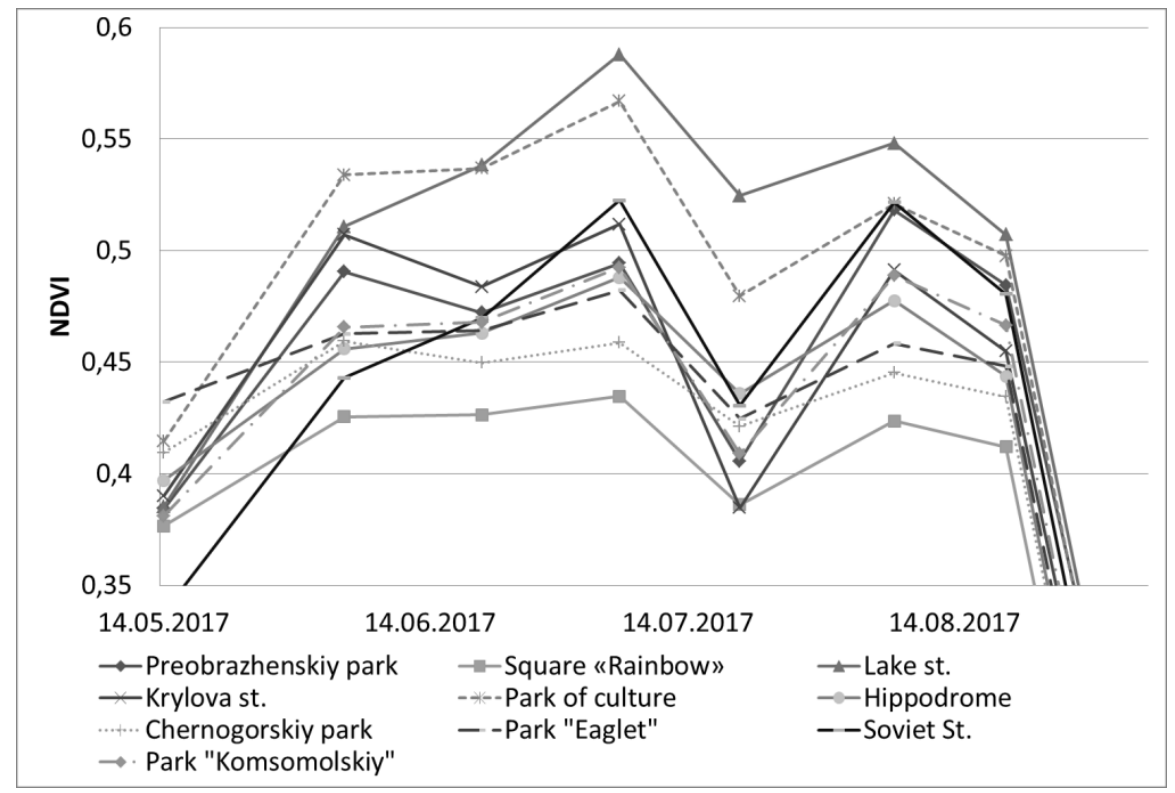

Fig. 1. Vegetation curve of NDVI green zones of the city of Abakan, 2017

All communities had similar data from 0.38 to 0.44 in mid-May 2017. The square «Rainbow» had a low NDVI throughout the season. The highest rates were observed on the Park of culture and Lake st. territories. The growth of biomass continued until the beginning of July, at which point most sites had indicators of $0.48-0.52$ and clearly differed in productivity. Then, a summer break in the growing season was observed until mid-July. A secondary growth of plants (in the range 0.4-0.5) is noted by the beginning of August, one is characteristic for the steppe zone.

The water content is critical for plants located in arid or urban environments. In this regard, the seasonal variation in moisture content was revealed (Fig. 2).
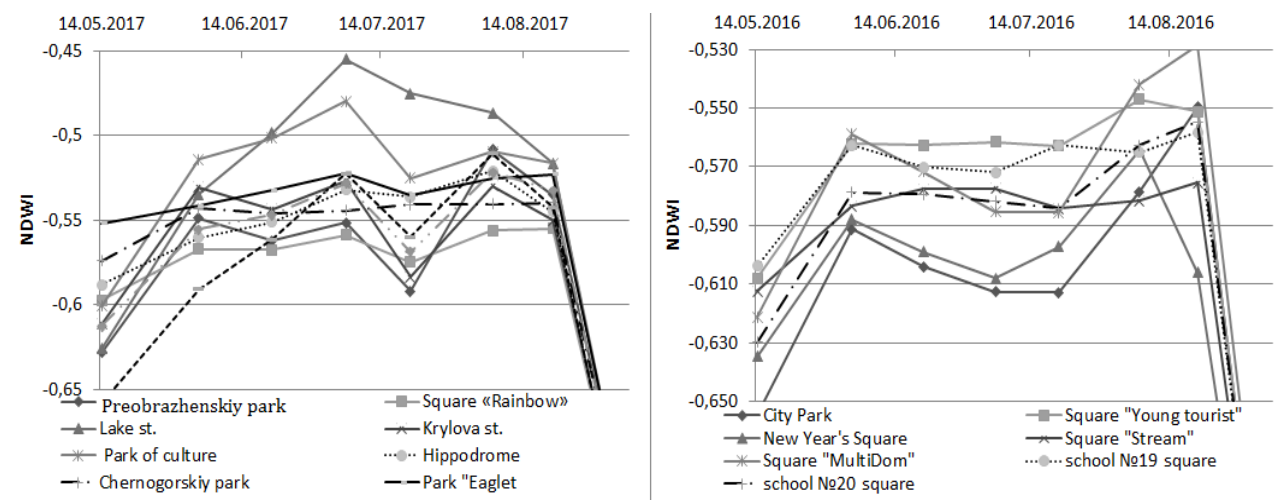

Fig. 2. Seasonal NDWI course of the green zones of Abakan (left) and Chernogorsk (right) 
The course of NDWI correlates with the course of the vegetation curve (Fig. 1). It reaches its maximum values for Abakan in the middle of the season (early July) as well as NDVI, for Chernogorsk - at the end of August. Intensive plant growth can occur if there is sufficient moisture. The average daily temperature in July was higher than the annual average values $\left(20.3^{\circ} \mathrm{C}\right.$ versus $\left.17.9^{\circ} \mathrm{C}\right)$, in June the figure was $18.6^{\circ} \mathrm{C}$, in August $16.9^{\circ} \mathrm{C}$ in Chernogorsk (2016), $133.7 \mathrm{~mm}$ of precipitation fell during the summer. A favorable period was a warm and humid August $(80.1 \mathrm{~mm})$, as evidenced by the secondary growth of NDVI and NDWI [3]. NDWI allows you to identify communities with a good water supply: for example, by a smooth decline on the Lake st. and hippodrome (Fig. 2). There is a drainage channel providing groundwater supply in the northern part of this area. There are poplar plantings, which is drought tolerant due to the deep root system.

The highest regression indicators of satellite and meteorological data were obtained for all areas during the period of active growth from 05/14/17 to 07/06/17 for Abakan (Table 3).

Table 3. Relations of meteorological and spectral indicators, Abakan

\begin{tabular}{|c|c|c|}
\hline Indicators & A regression equation & $\mathrm{R}^{2}$ \\
\hline NDVI and the sum of the temperatures & $y=0.0005 x+0.3244$ & 0.60 \\
\hline NDWI and NDVI & $y=0.6266 x-0.8354$ & 0.95 \\
\hline NDWI and HTC & $y=0.1938 \ln x-0.7466$ & 0.74 \\
\hline NDVI and HTC & $y=0.8715 e^{2.45 x}$ & 0.73 \\
\hline
\end{tabular}

A significant dependence of the parameters is noticeable. The equation of NDVI and HTC showed a coefficient of determination of 0.73 , between HTC and NDWI -0.74 .

\section{Conclusion}

Higher indices were observed in areas where vegetation is subject to care, watering and fertilizing, and young trees (5-8 years old) are found in the composition. The indicator for parks with trees over 20 years old is reduced. The growth rate in Chernogorsk is higher in comparison with Abakan, due to the late passage of the phenophases. Most of the investigated green areas lack moisture according to the NDWI index. Meteorological and spectral indicators showed a significant degree of positive correlation (0.60-0.74).

\section{References}

1. O. N. Vorobyev, E. A. Kurbanov, A. V. Gubayev, Yu. A. Polevshchikova, E. N. Demisheva, V. O. Koptelov, Bulletin of the povolga state technological university, 1(25), 5-21 (2015)

2. M. Maximov, A. Skachkova, D. Kurlovich, Land of Belarus, 4, 42-44 (2016)

3. M. A. Leshchinskaya, E. G. Lagunova, E. Yu. Zhukova Bulletin of KrasGAU, 2(137), 183-188 (2018)

4. I. M. Krasnoborov et al., Key to plants of the south of the Krasnoyarsk territory (Novosibirsk, 1979)

5. Flora of Siberia 1-14 (Novosibirsk, 1987-2003)

6. T.K. Goryshina, Plant Ecology (Moscow, 1979)

7. I. G. Serebryakov, Ecological morphology of plants. Life forms of angiosperms and conifers (Moscow, 1962)

8. D. Chen, J. Huang, T. J. Jackson, Remote Sensing of Environment, 98, 225-236 (2005)

9. A. V. Panin, M. A. Berezutsky, Botanicheskii Zhurnal. 92(8), 1144-1154 (2007)

10. E. S. Ankipovich, Catalog of Flora of the Republic of Khakasia (Barnaul, 1999)

11. M. A. Berezutsky, Botanicheskii Zhurnal. 83(9), 77-83 (1998) 